\title{
Papers
}

\section{Randomised controlled trial of labouring in water compared with standard of augmentation for management of dystocia in first stage of labour}

Elizabeth R Cluett, Ruth M Pickering, Kathryn Getliffe, Nigel James St George Saunders

\begin{abstract}
Objectives To evaluate the impact of labouring in water during first stage of labour on rates of epidural analgesia and operative delivery in nulliparous women with dystocia.

Design Randomised controlled trial.

Setting University teaching hospital in southern England. Participants 99 nulliparous women with dystocia (cervical dilation rate $<1 \mathrm{~cm} /$ hour in active labour) at low risk of complications.

Interventions Immersion in water in birth pool or standard augmentation for dystocia (amniotomy and intravenous oxytocin).

Main outcome measures Primary: epidural analgesia and operative delivery rates. Secondary: augmentation rates with amniotomy and oxytocin, length of labour, maternal and neonatal morbidity including infections, maternal pain score, and maternal satisfaction with care.

Results Women randomised to immersion in water had a lower rate of epidural analgesia than women allocated to augmentation $(47 \% v 66 \%$, relative risk 0.71 (95\% confidence interval 0.49 to 1.01), number needed to treat for benefit (NNT) $5)$. They showed no difference in rates of operative delivery ( $49 \%$ v 50\%, 0.98 (0.65 to 1.47), NNT 98), but significantly fewer received augmentation ( $71 \% v 96 \%, 0.74$ (0.59 to 0.88$)$, NNT 4$)$ or any form of obstetric intervention (amniotomy, oxytocin, epidural, or operative delivery) ( $80 \% v 98 \%, 0.81$ ( 0.67 to 0.92$)$, NNT 5). More neonates of women in the water group were admitted to the neonatal unit $(6 v 0, \mathrm{P}=0.013)$, but there was no difference in Apgar score, infection rates, or umbilical cord $\mathrm{pH}$. Conclusions Labouring in water under midwifery care may be an option for slow progress in labour, reducing the need for obstetric intervention, and offering an alternative pain management strategy.
\end{abstract}

\section{Introduction}

Slower than expected progress in the first stage of labour (dystocia) occurs in $20 \%$ of nulliparous women in labour and accounts for $20 \%$ of caesarean sections and $40 \%$ of instrumental deliveries, and results in longer hospitalisation. ${ }^{1}$ For women at low risk of complications, it marks the transition from midwifery to obstetric management. Since proponents of active management first claimed the benefits of shorter labour and lower rates of caesarean section, ${ }^{2}{ }^{3}$ debate has continued over conservative versus aggressive management and the medicalisation of birth. Management strategies for dystocia vary from immediate augmentation ${ }^{45}$ to delayed intervention up to four hours after diagnosis. ${ }^{6-8}$ Comparison between strategies is difficult as specific features often differ; for example, one-to-one care is recognised to have beneficial effect on labour outcomes. ${ }^{9}$

Our current trial was based on two precepts. Firstly, that incomplete understanding of labour may lead to unnecessarily early intervention. Secondly, that anxiety and pain may trigger a stress response, ${ }^{10}$ leading to reduced uterine activity and dystocia. ${ }^{11}$ Labouring in water may ameliorate this stress response by aiding relaxation and pain relief. Few trials have evaluated labouring in water, perhaps because of the difficulty in randomising women who may have strong preferences. ${ }^{12} \mathrm{~A}$ Cochrane review concluded that, for women at low risk of complications, there was no clear evidence of advantage or disadvantage in using a pool in labour but further research was needed. ${ }^{13}$ Two national surveys concluded that labour and birth in water had no effect on perinatal mortality. ${ }^{15}$

In preparation for the trial reported here, we conducted a feasibility study comparing labour in water with augmentation and conservative management for women with dystocia, ${ }^{16}$ but conservative management was considered unacceptable by women and clinicians. Our current trial therefore compares labour in water with augmentation in nulliparous women with dystocia.

\section{Participants and methods}

\section{Design}

Our randomised controlled trial compared immersion in water during the first stage of labour after diagnosis of dystocia with augmentation, the standard management for dystocia. We conducted the trial between January 1999 and December 2000 in a large university teaching hospital in southern England with about 4500 births a year.

\section{Study population}

Nulliparous women with a diagnosis of dystocia (cervical dilation of $<1 \mathrm{~cm} /$ hour) - who at that time would routinely have been advised to have their labour augmented by amniotomy or oxytocin infusion, or both-were eligible for the trial if they were able to give informed consent, had received information about the trial during their pregnancy (a leaflet describing the trial was distributed to all nulliparous women antenatally), were in spontaneous, active labour, and were at low risk of complications (full term, singleton pregnancies, fetus in cephalic presentation, and no medical, obstetric, or psychiatric problems). 


\section{Intervention}

After participating women were randomised, each management option consisted of a package of care provided by midwives, including one-to-one care. Labour progress was assessed by vaginal examinations every four hours and documented on a standard partogram. All women could request any form of analgesia available at any time.

Augmentation-Women in the augmentation group received the standard management for dystocia. Amniotomy was performed if the membranes were intact, and a midwife managed the labour for the next two hours unless otherwise clinically indicated. If the membranes were already ruptured or progress was not satisfactory during the two hours after amniotomy, intravenous oxytocin was given, starting at 4 $\mathrm{mU} / \mathrm{min}$ and doubled every 30 minutes, up to a maximum of 64 $\mathrm{mU} / \mathrm{min}$, until regular contractions (3-4 every 10 minutes) occurred. Continuous fetal monitoring was carried out.

Labour in water-Women allocated to labour in water used a permanent, acrylic, oval waterbirth pool measuring $154 \mathrm{~cm}$ by $184 \mathrm{~cm}$ by $77 \mathrm{~cm}$ and filled with still tap water without additives so that immersion was to above the breasts when sitting. Water temperature was maintained at $36.0-37.0^{\circ} \mathrm{C}$. The maximum stay in the pool before reassessment by vaginal examination was four hours. If labour progress was satisfactory (cervical dilation $\geq 1 \mathrm{~cm}$ /hour), subsequent care could continue in the pool if the woman wished, otherwise augmentation was advised.

\section{Sample size}

We based our estimate of the potential effect size on an audit of 50 nulliparous women with dystocia in May-July 1997, who would have met the trial inclusion criteria. We concluded that 220 women would be required to detect an absolute reduction of $25 \%$ in the rate of epidural analgesia (from $60 \%$ to $35 \%$ ) and an absolute reduction of $20 \%$ in the operative delivery rate (from $40 \%$ to $20 \%$ ) with $90 \%$ power in $5 \%$ two sided tests. The local incidence of dystocia in nulliparous women meeting our eligibility criteria was about five a week (260 a year). In our pilot study we obtained a consent rate of $71 \%,{ }^{16}$ but we anticipated a lower rate when all midwives undertook recruitment, and therefore planned a recruitment period of two years.

\section{Randomisation and recruitment}

We used a computer generated randomisation schedule in balanced blocks of 20. Concealment was ensured by an independent person putting allocation details in sequentially numbered, opaque, sealed envelopes. Ten consecutively numbered envelopes were stored in the labour ward at any one time and audited daily to ensure they were intact. After dystocia was diagnosed, a midwife who had received training in patient recruitment checked that the woman in question had received the information leaflet about the trial, assessed her eligibility for the study, and, if suitable, sought her informed consent. When a woman agreed to participate the midwife opened the next trial envelope to allocate the woman to a treatment arm and to give her a unique trial number. Participation in the trial was recorded in the woman's routine maternity records.

\section{Outcome measures}

Primary outcome measures were epidural analgesia and operative delivery (ventouse, forceps, or caesarean section). Secondary measures included augmentation rates (receiving amniotomy or oxytocin, or both) and maternal or neonatal morbidity (any infection, admission to the neonatal unit, or condition that required medical care up to the 10th postpartum day). Obstetric data were recorded in the maternity records by practi- tioners and abstracted after discharge from maternity care. It was not possible to conceal allocation from clinical practitioners or at the time of data abstraction as care provided was clearly documented. However, as data were objective in nature and recorded contemporaneously observer bias was minimised.

We conducted a postpartum structured interview in the maternity unit to assess retrospectively the women's experience of pain at 30 minutes after the intervention started and change in pain over the same time period (measured with visual analogue scales of 0 to $100 \mathrm{~mm}$ for pain experience and $-50 \mathrm{~mm}$ to $+50 \mathrm{~mm}$ for change in pain). We did not assess pain concurrently because of the disruption to the women and midwives. We also assessed women's satisfaction overall and in relation to privacy and freedom of movement (asked as separate questions) using four point Likert scales. We chose to use a structured interview format to reduce potential bias because it was not possible to keep the interviewer blinded to women's treatments as their comments made the allocation apparent.

\section{Statistical analysis}

We analysed results on an intention to treat basis. We compared rates of epidural analgesia and operative delivery between groups using Pearson's $\chi 2$ tests and presented results as relative risks with $95 \%$ confidence intervals. When numbers were small we calculated exact $\mathrm{P}$ values and confidence intervals in StatXact-5. We produced numbers needed to treat to produce benefit in one woman and calculated confidence intervals as the inverse of the confidence interval about the absolute risk difference. Confidence intervals around the numbers needed to treat for non-significant differences include the numbers needed to treat to produce harm ${ }^{17}$ showing that results are not inconsistent with the intervention producing worse outcome. We used MannWhitney tests to compare length of labour and women's pain and satisfaction scores, and presented confidence intervals for differences in means.

A confidential summary of the safety data was prepared after 50 women had been randomised, and assessed by an obstetric consultant independent of the trial, who recommended that recruitment continue.

\section{Results}

\section{Recruitment}

Of 3825 nulliparous women who delivered in the unit during the two years of recruitment, 741 were defined as being at low risk of complications at the time of the diagnosis of dystocia (see figure). Consent was sought from 176 eligible women, of whom 99 $(56 \%)$ agreed to participate, and were randomised. The two groups of women showed no important differences in baseline characteristics (table 1). There was good adherence to the trial protocol, with 48 of the 49 women allocated to labour in water using the pool, and 48 of the 50 women allocated to standard care receiving augmentation. The woman who declined to enter the water requested an amniotomy. Two women in the augmentation group progressed before augmentation could be started.

\section{Primary outcomes}

Twenty three women (47\%) allocated to labour in water received epidural analgesia after randomisation compared with $33(66 \%)$ in the augmentation group (relative risk 0.71 (95\% confidence interval 0.49 to 1.01 ), number needed to treat 5) (table 2). The numbers of operative deliveries (caesarean sections and ventouse and forceps deliveries) were similar in both arms of the trial, with $24(49 \%)$ women allocated to labour in water receiving an operative delivery compared with $25(50 \%)$ women allocated 


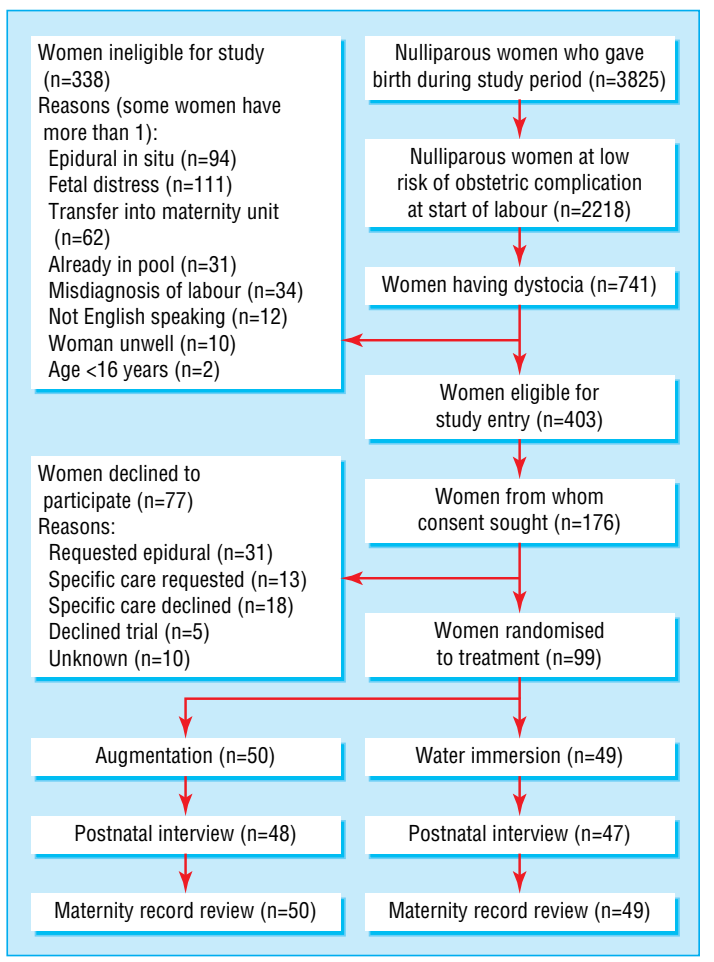

Flow of participants through trial

to augmentation (relative risk 0.98 (0.65 to 1.47$)$, number needed to treat 98$)$.

\section{Secondary outcomes}

Twenty five of the 27 women in the water labour arm who had made slow progress at the assessment four hours after recruitment received augmentation. A further three women progressed slowly subsequently and also received augmentation. Seven women who progressed satisfactorily received an

Table 1 Baseline characteristics of nulliparous women with dystocia allocated to labour in a birth pool or standard augmentation (amniotomy and intravenous oxytocin). Values are numbers (percentages) of women unless otherwise indicated

\begin{tabular}{|c|c|c|}
\hline Characteristics & Labour in water $(n=49)$ & Augmentation $(n=50)$ \\
\hline $\begin{array}{l}\text { Mean (SD, range) maternal age } \\
\text { (years) }\end{array}$ & $26.0(4.8,17-37)$ & $24.8(6.0,17-38)$ \\
\hline \multicolumn{3}{|l|}{ Gravida: } \\
\hline 1 & $39(80)$ & $36(72)$ \\
\hline 2 & 7 (14) & 11 (22) \\
\hline 3 & $3(6)$ & $3(6)$ \\
\hline $\begin{array}{l}\text { Mean (SD, range) birth weight } \\
(\mathrm{g})\end{array}$ & $3502(427,2640-4630)$ & $3417(484,2450-4810)$ \\
\hline $\begin{array}{l}\text { Mean (SD, range) gestational } \\
\text { age at start of labour (days) }\end{array}$ & $284(7,264-294)$ & $280(8,260-294)$ \\
\hline \multicolumn{3}{|l|}{ Marital status: } \\
\hline Single & $16(33)$ & $21(42)$ \\
\hline Married & $23(47)$ & $23(46)$ \\
\hline Stable relationship & $10(20)$ & $6(12)$ \\
\hline \multicolumn{3}{|l|}{$\begin{array}{l}\text { Mean (SD, range) cervical } \\
\text { dilation }(\mathrm{cm}) \text { : }\end{array}$} \\
\hline When labour established & $4.24(1.12,3.0-8.0)$ & $4.22(1.14,3.0-8.0)$ \\
\hline When dystocia diagnosed & $5.31(1.41,3.0-8.5)$ & $5.26(1.41,3.0-9.0)$ \\
\hline When randomised & $5.31(1.40,3.0-8.5)$ & $5.28(1.37,3.0-9.0)$ \\
\hline $\begin{array}{l}\text { Mean (SD, range) cervical } \\
\text { dilation between start of } \\
\text { labour and randomisation } \\
\text { (cm/hour) }\end{array}$ & $0.27(0.24,-0.22-0.72)$ & $0.25(0.28,-0.38-1.2)$ \\
\hline
\end{tabular}

amniotomy for other indications. The number of women who received augmentation (amniotomy or oxytocin) in the water labour arm was significantly lower than that in the standard care arm (35 (71\%) v 48 (96\%), relative risk 0.74 (0.59 to 0.88$)$, number needed to treat 4 ) (table 2).

The mean duration of the first stage of labour was similar in the two groups, 10.47 hours in the water labour group and 10.26 hours in the augmentation group (table 3). Women allocated to labour in water reported significantly lower mean pain scores at 30 minutes after start of the allocated management ( $49 \mathrm{~mm} v 64$ $\mathrm{mm})$ and a reduction in mean pain $(-26 \mathrm{~mm})$ compared with an increase for women receiving augmentation (12 $\mathrm{mm})$. Women allocated to labour in water were more likely to report satisfaction with freedom of movement $(91 \% v 63 \%)$ and with experience of privacy $(96 \% v 81 \%)$, but there was no difference between groups in overall satisfaction (table 3).

\section{Maternal and neonatal wellbeing}

Maternal and neonatal infection rates were similar in the two groups (table 4), as was neonatal condition at birth indicated by Apgar score and umbilical cord $\mathrm{pH}$. Six neonates born to women in the water labour group were admitted to the neonatal unit compared with none in the augmentation group $(\mathrm{P}=0.013)$. The reasons for admission were: cardiac defects (1), hypothermia (2), fever (1), suspected infection on day 2 (1), and poor feeding on day 3 (1). There was a mean delay of 6 hours (range 2-10 hours) between women leaving the pool and birth. With the exception of the infant with cardiac defects, all these neonates, who had required an operative delivery, were reunited with their mothers within 48 hours and experienced no subsequent problems.

\section{Discussion}

This is the first trial to evaluate the impact of labouring in water for nulliparous women with dystocia. Compared with women given standard augmentation, the women labouring in water had no difference in operative delivery rates and tended to receive less epidural analgesia. Before this trial it had been suggested that as all the women would have dystocia, augmentation would be inevitable, along with longer labour, and/or assistance in the second stage of labour. However, almost $30 \%$ of women in the water arm did not receive augmentation and 20\% received no obstetric intervention, without evidence of longer labour, both of these rates being significantly different from the augmentation arm. In addition, women retrospectively reported less pain and increased satisfaction.

Our findings suggest that delaying augmentation in association with a supportive environment (water immersion) is acceptable to women with dystocia and may reduce the need for epidural analgesia without increasing labour length or operative deliveries. This is important, as it has been suggested that women prefer earlier intervention. ${ }^{7}$ Also a management approach that reduces rates of augmentation and associated obstetric intervention may contribute positively to maternal physiological and psychological health: oxytocin infusion is known to increase the risk of uterine hyperstimulation and fetal hypoxia, and obstetric interventions are associated with lower maternal satisfaction. ${ }^{18} \mathrm{~A}$ reduced need for epidural analgesia and augmentation may enable staff and other resources to be used differently-for example, allowing more women to receive one-to-one care in labour.

\section{Maternal and neonatal wellbeing}

The trial was not large enough to detect differences in maternal and fetal morbidity. However, indicators of wellbeing were simi- 
Table 2 Epidural analgesia, mode of delivery, and secondary outcomes among nulliparous women with dystocia allocated to labour in a birth pool or standard augmentation (amniotomy and intravenous oxytocin). Values are numbers (percentages) of women unless otherwise indicated

\begin{tabular}{|c|c|c|c|c|c|}
\hline Outcomes & Labour in water ( $n=49$ ) & Augmentation $(\mathrm{n}=50)$ & Relative risk (95\% Cl) & $\begin{array}{l}\text { Number needed to treat to } \\
\text { benefit one woman (NNTB) } \\
(95 \% \mathrm{CI})\end{array}$ & Pearson $\chi 2 \mathrm{P}$ value \\
\hline \multicolumn{6}{|l|}{ Epidural analgesia: } \\
\hline At first stage of labour & $21(43)$ & $30(60)$ & & & \\
\hline At second stage of labour & $2(4)$ & $3(6)$ & & & \\
\hline At any stage of labour & $23(47)$ & $33(66)$ & 0.71 (0.49 to 1.01) & 5 (3 to $\infty$ to NNTH -212$)$ & 0.056 \\
\hline \multicolumn{6}{|l|}{ Mode of delivery: } \\
\hline Normal & $25(51)$ & $25(50)$ & & & \\
\hline Ventouse & $12(25)$ & $10(20)$ & & & \\
\hline Forceps & $4(8)$ & $4(8)$ & & & \\
\hline Caesarean section & $8(16)$ & $11(22)$ & & & \\
\hline Any operative delivery & $24(49)$ & $25(50)$ & 0.98 (0.65 to 1.47) & $98(3$ to $\infty$ to NNTH -5$)$ & 0.919 \\
\hline \multicolumn{6}{|l|}{ Method of augmentation: } \\
\hline Amniotomy & $28(57)$ & $37(74)$ & & & \\
\hline Amniotomy alone & $14(29)$ & $20(40)$ & & & \\
\hline Oxytocin & $21(43)$ & $28(56)$ & & & \\
\hline Oxytocin alone & $7(14)$ & $11(22)$ & & & \\
\hline Amniotomy and oxytocin & $14(29)$ & $17(34)$ & & & \\
\hline $\begin{array}{l}\text { Amniotomy or oxytocin, or } \\
\text { both }\end{array}$ & $35(71)$ & $48(96)$ & 0.74 (0.59 to 0.88$)$ & 4 (3 to 9$)$ & 0.001 \\
\hline Any obstetric intervention* & $39(80)$ & 49 (98) & 0.81 (0.67 to 0.92$)$ & 5 (3 to 14) & 0.004 \\
\hline
\end{tabular}

NNTH=Number needed to treat to harm one woman.

${ }^{*}$ Amniotomy, oxytocin, epidural analgesia, or operative delivery.

lar in the two groups, with the exception of increased admission to the neonatal unit after labour in water. Possible reasons for this include the water immersion itself, the delay in intervention of up to four hours (even though this did not affect overall labour length), extra caution by practitioners when women were known to have laboured in water, or chance factors with no direct relation to the trial. No other studies of labour in water have reported such an association: instead, they either did not provide data on admissions to neonatal units ${ }^{19}{ }^{20}$ or reported only one admission ${ }^{21}$ or similar admission rates in both trial arms. ${ }^{22}$ Eckert et al reported an increased incidence of initial resuscitation measures with water immersion, ${ }^{22}$ but we found no difference in Apgar scores and blood gas analysis at birth. Indeed, three of the admissions to the neonatal unit were between nine and 48 hours after delivery, while the three admissions immediately after birth were associated with temperature regulation. Comparative studies of labour in water found no increase in admissions to neonatal units or other markers of neonatal distress. ${ }^{23-25}$ It is clearly important to ensure ongoing audit of neonatal outcomes for women who labour in water.

Table 3 Labour length and retrospectively reported pain and satisfaction among nulliparous women with dystocia allocated to labour in a birth pool or standard augmentation (amniotomy and intravenous oxytocin). Values are numbers (percentages) of women unless otherwise indicated

\begin{tabular}{|c|c|c|c|c|}
\hline Outcomes & Labour in water ( $n=49$ ) & Augmentation $(n=50)$ & Mean differences $(95 \% \mathrm{Cl})$ & $P$ value \\
\hline $\begin{array}{l}\text { Mean (SD, range) length of first stage of } \\
\text { labour (hours) }\end{array}$ & $10.47(3.69,3.75-19.32)$ & $10.26(3.75,4.25-21.37)$ & $0.22(-1.27$ to 1.70$)$ & $0.677 \dagger$ \\
\hline \multicolumn{5}{|l|}{ Pain score (visual analogue scale) ${ }^{\star}$ : } \\
\hline $\begin{array}{l}\text { Mean (SD, range) pain score } 30 \text { minutes } \\
\text { after start of management }(0-100 \mathrm{~mm})\end{array}$ & $49(22,8-96)$ & $64(30,0-100)$ & $-16(-27$ to -5$)$ & $0.003 \dagger$ \\
\hline $\begin{array}{l}\text { Mean (SD, range) change in score after } \\
30 \text { minutes of management ( }-50 \text { to } 50 \\
\mathrm{~mm} \text { ) }\end{array}$ & $-26(16,-50-28)$ & $12(32,-50-50)$ & -38 (-49 to 28$)$ & $<0.001 \dagger$ \\
\hline Maternal satisfaction & $(n=47)^{*}$ & $(\mathrm{n}=48)^{*}$ & Relative risk of satisfaction (95\% CI) & \\
\hline \multicolumn{5}{|l|}{ With freedom of movement: } \\
\hline Satisfied & $43(91)$ & $30(63)$ & \multirow{4}{*}{$1.46(1.18$ to 1.91$)$} & \multirow{4}{*}{$0.001 \neq$} \\
\hline Satisfied and dissatisfied & $4(9)$ & $15(31)$ & & \\
\hline Dissatisfied & 0 & 0 & & \\
\hline Not sure & 0 & $3(6)$ & & \\
\hline \multicolumn{5}{|l|}{ With privacy: } \\
\hline Satisfied & $45(96)$ & $39(81)$ & \multirow{4}{*}{$1.18(1.02$ to 1.42$)$} & \multirow{4}{*}{$0.029 \ddagger$} \\
\hline Satisfied and dissatisfied & $2(4)$ & $9(19)$ & & \\
\hline Dissatisfied & 0 & 0 & & \\
\hline Not sure & 0 & 0 & & \\
\hline \multicolumn{5}{|l|}{ With overall management: } \\
\hline Satisfied & $44(94)$ & $42(88)$ & \multirow{4}{*}{1.07 (0.93 to 1.26$)$} & \multirow{4}{*}{$0.486 \S$} \\
\hline Satisfied and dissatisfied & $2(4)$ & $6(13)$ & & \\
\hline Dissatisfied & $1(2)$ & 0 & & \\
\hline Not sure & 0 & 0 & & \\
\hline
\end{tabular}

*Postnatal interviews were conducted for 48 women allocated to augmentation and 47 women allocated to labour in water. A further two women in each group declined to answer the pain questions.

†Mann-Whitney test. ‡Pearson $\chi^{2}$ test. $\S$ Exact $\chi^{2}$ and confidence interval. 
Table 4 Maternal and neonatal morbidity, including infection, for nulliparous women with dystocia allocated to labour in a birth pool or standard augmentation (amniotomy and intravenous oxytocin). Values are numbers (percentages) unless otherwise indicated

\begin{tabular}{|c|c|c|c|}
\hline Outcomes & $\begin{array}{l}\text { Labour in water } \\
\qquad(n=49)\end{array}$ & Augmentation $(n=50)$ & $P$ value \\
\hline \multicolumn{4}{|l|}{ Maternal wellbeing } \\
\hline Infection in first 10 days & $3(6)$ & $5(10)$ & $0.715^{*}$ \\
\hline \multicolumn{4}{|l|}{ Neonatal wellbeing } \\
\hline \multicolumn{4}{|l|}{ Apgar score at 5 minutes: } \\
\hline 8 & $1(2)$ & 0 & $0.203 \dagger$ \\
\hline 9 & $40(82)$ & 47 (94) & \\
\hline 10 & $8(16)$ & $3(6)$ & \\
\hline $\begin{array}{l}\text { Mean (SD, range) arterial } \\
\text { umbilical cord pH }\end{array}$ & $\begin{array}{l}7.26(0.07 \\
7.10-7.39)\end{array}$ & $7.25(0.07,7.11-7.36)$ & $0.965 \dagger$ \\
\hline $\begin{array}{l}\text { Admission to neonatal unit } \\
\text { in first } 10 \text { days }\end{array}$ & $6(12)$ & 0 & $0.013^{*}$ \\
\hline Infection in first 10 days§: & $8(17)$ & $9(18)$ & $0.783 \rrbracket$ \\
\hline Eye(s) & 5 & 6 & \\
\hline Mouth & 2 & 2 & \\
\hline Umbilicus & 0 & 1 & \\
\hline Skin & 1 & 0 & \\
\hline Penis & 1 & 1 & \\
\hline Raised white cell count & 1 & 0 & \\
\hline $\begin{array}{l}\text { Raised C reactive } \\
\text { protein level }\end{array}$ & 0 & 1 & \\
\hline
\end{tabular}

${ }^{*}$ Exact $\chi^{2}$ test.

†Mann-Whitney test.

fUmbilical cord $\mathrm{pH}$ analysis undertaken in only 35 neonates from labour in water group and 39 from augmentation group.

§Some neonates had more than one condition.

IPearson $\chi^{2}$ test.

\section{Limitations of study}

Only 99 of the intended 220 women were recruited for a variety of reasons. In common with other trials ${ }^{18}$ epidural analgesia was the main reason why nulliparous women with dystocia were ineligible for our study (28\%). Local rates of epidural analgesia and their likely impact on recruitment should feature as part of the planning of any future trials involving labour management. In our busy maternity unit recruitment was not a priority, and some eligible women were not invited to participate in our study. The main reason eligible women chose not to enter the trial was a preference for one or other form of care (40\%). This is a recognised problem, and consideration is needed on how this may affect the generalisability of our findings and ways to overcome recruitment problems.

Recruitment became more difficult towards the end of the trial because of the adoption of a more conservative approach to managing dystocia in the unit and the introduction of the modified World Health Organization partogram, ${ }^{6}$ which incorporates a delay between the identification of slow progress and augmentation. During this delay midwives could facilitate ongoing conservative management; as a consequence, they were less willing to recruit women to the trial, knowing that half of the women would immediately receive augmentation. Thus, the trial was not continued past the planned two years. The low recruitment rate contributed to the outcomes achieved, such as the lack of statistical significance in relation to the difference in rates of epidural analgesia.

We thank the women who participated in the trial; the midwives and obstetric and support staff of the unit where the trial was conducted; research advisory group members Maggie Elliot and Debbie Gould; and Rona McCandlish for her support in preparing this paper.

Contributors: ERC was principal investigator and research midwife and was responsible for trial design and coordination, and data collection and analysis, supported by RMP and KG as research supervisors. NJS

\section{What is already known on this topic}

For women in normal labour, immersion in water is associated with less need for analgesia and increased satisfaction

Augmentation of labour, in particular oxytocin administration, is associated with hyperstimulation and decreased maternal satisfaction

\section{What this study adds}

For nulliparous women with dystocia (cervical dilation $<1$ $\mathrm{cm} /$ hour), immersion in water for up to four hours seemed to reduce need for augmentation of labour, reduce pain, and increase satisfaction, without increasing overall length of labour or operative delivery rate

Water immersion may be an alternative option to early augmentation of labour

contributed to the initial idea and enabled the trial in the clinical setting. All authors helped to write the paper. ERC acts as guarantor for the paper. Funding: Southampton University Hospitals NHS Trust.

Competing interest: None declared.

Ethical approval: Approval was given by the local research ethics committee.

1 Department of Health. NHS maternity statistics, England $1989 / 90$ to 1994/95. Statistical Bulletin No 28. London: Stationery Office, 1997:1-16.

Johanson R, Newburn M, MacFarlane A. Has the medicalisation of childbirth gone too far? BMJ 2002;324:892-5.

3 Impey L, Boylan P. Active management of labour revisited. $\mathrm{Br} J$ Obstet Gynaecol 1999;106:183-7.

4 Cammu H, Van Eeckhout E. A randomised controlled trial of early versus delayed use of amniotomy and oxytocin infusion in nulliparous labour. Br J Obstet Gynaecol 1996;103:313-8.

5 Sadler LC, Davison T, McCowen LME. A randomised controlled trial and meta analysis of active management of labour. Br J Obstet Gynaecol 2000;107:909-15.

6 World Health Organisation maternal health and safe motherhood programme. World World Health Organisation maternal health and safe motherhood programme. World
Health Organisation partograph in the management of labour. Lancet 1994;343:1399Heal 404 .

7 Blanch G, Lavender T, Walkinshaw S, Alfirevic A. Dysfunctional labour: a randomised trial. BrJ Obstet Gynaecol 1998;105:117-20.

8 Lavender T, Walkinson S, Walton I. A prospective study of women's views of factors contributing to a positive birth experience Midwifery 1999;15:40-6.

Hodnett ED. Support from caregivers during childbirth. (Cochrane review) In: Cochrane Library. Issue 1. Oxford: Update Software, 2003.

10 Brownridge P. The nature and consequence of childbirth pain. Eur J Obstet Gynecol Reprod Biol 1995;32(suppl):S9-15.

11 De Punzio C, Neri E, Metelli P, Bianchi MS, Venticinqui M, Ferdeghini M, et al. The De Punzio C, Neri E, Metelli P, Bianchi MS, Venticinqui M, Ferdeghini M, et al. The
relationship between maternal relaxation and plasma beta endorphin levels during parturition. J Psychosom Obstet Gynaecol 1994;15:205-10.

12 Garland D, Jones K. Waterbirth, first stage immersion or non immersion? Br J Midwifery 1994;2(3):113-20.

13 Nikodem VC. Immersion in water during pregnancy, labour and birth. In: Cochrane Library. Issue 1. Oxford: Update Software, 2003.

14 Gilbert RE, Tookey PA. Perinatal mortality and morbidity among babies delivered in water; surveillance study and postal survey. BMJ 1999;319:483-7.

15 Alderdice F, Renfrew M, Marchant S, Ashurst H, Hughes P, Berridge G, et al. Labour and birth in water in England and Wales. BMJ 1995;310:837.

16 Cluett ER, Pickering RM, Brooking JI. An investigation into the feasibility of comparing three management options (augmentation, conservative and water) for nulliparae ing three management options (augmentation, conservative and
with dystocia in the first stage of labour. Midwifery 2001:17:35-43.

17 Altman DG. Confidence intervals for the number needed to treat. BMJ 1998;317:130912.

18 Green JM, Coupland VA, Kitzinger JV. Great expectations. A prospective study of women's expectations and experiences of childbirth. 2nd ed. Cheshire: Books for Midwives, 1998.

19 Schorn MN, McAllister JL, Blanco JD. Water immersion and the effect on labor.J Nurse Midwifery 1993;38:336-42.

20 Rush J, Burlock S, Lambert K, Loasley-Milman M, Hutchinson B, Enkin M. The effects of whirlpool baths in labour: a randomised controlled trial. Birth 1996;23:136-43.

21 Cammu H, Clasen K, Wettere L, Derde M-P. To bathe or not to bathe during the first stage of labor. Acta Obstet Gynecol Scand 1994;73:468-72.

22 Eckert K, Turnbull D, MacLennan A. Immersion in water in the first stage of labour: a Eckert K, Turnbull D, MacLennan A. Immersion

23 Aird IA, Luckas MJM, Buckett WM, Bousfielf P. Effects intrapartum hydrotherapy on labour parameters. Aust N Z J Obstet Gynaecol 1997;37:137-42.

24 Otigbah CM, Dhanjal MK, Harmsworth G. A retrospective comparison of water births and conventional vaginal deliveries. Eur J Obstet Gynecol Reprod Biol 2000;91:15-20. 
25 Ohlsson G, Buchhave P, Leandersson U, Nordstrom L, Rydhstrom H, Sjolin I. Warm tub bathing during labor; maternal and neonatal effects. Acta Obstet Gynecol Scand 2001;80:311-4.

(Accepted 18 November 2003)

doi 10.1136/bmj.37963.606412.EE

Nightingale Building (67), University of Southampton, Southampton SO17 1BJ Elizabeth R Cluett lecturer in midwifery
Kathryn Getliffe professor of nursing

Medical Statistics Group, Health Care Research Unit (805), Southampton General Hospital, Southampton SO16 6YD

Ruth M Pickering senior lecturer in medical statistics

Trust Management Office (Mail point 18), Southampton General Hospital, Southampton SO16 6YD

Nigel James St George Saunders medical director

Correspondence to: E R Cluett ec1@soton.ac.uk 